\section{Medicina, filosofía y literatura: senderos que se (re)encuentran}

\author{
Medicine, philosophy and \\ literature: (re)uniting paths
}

Hasta tiempos relativamente recientes en la historia de la humanidad, las disciplinas que hoy dividimos en científicas y humanísticas se consideraban parte de un todo y eran estudiadas de esa manera. Como es bien sabido, durante el renacimiento y la ilustración ser polímata, es decir, adquirir conocimiento y desarrollar habilidades en todos los campos del saber, era el gran ideal a alcanzar. Este fenómeno no se abocaba de manera exclusiva al mundo intelectual; mujeres y hombres comunes eran en gran medida generalistas: en una casa se sabía cómo producir los propios alimentos (desde la obtención de materias primas), elaborar la vestimenta, construir o reparar objetos de uso cotidiano, así como curar o aliviar padecimientos ordinarios. De igual forma, las ahora consideradas prácticas de la alta cultura como leer obras literarias y filosóficas, ir al teatro o practicar algún instrumento eran formas de entretenimiento casi universales. Con la especialización del conocimiento, que comenzó a darse de manera conspicua con la Revolución Industrial y prosperó de manera aún más acelerada a partir de la segunda mitad del siglo veinte, la especie humana ha logrado avances científicos y tecnológicos con que los polímatas renacentistas e ilustrados no hubieran podido siquiera soñar. Algo, sin embargo, se ha perdido con la sobreespecialización y la división tajante entre lo humano y lo científico.

Valores y virtudes y Ética en obra abordan justamente aquello que se ha dejado de lado en el área de la salud humana a consecuencia de la separación del conocimiento, el desarrollo tecnocientífico y la ponderación de las ciencias básicas por encima de lo humano: los valores y las virtudes. Un nutrido grupo de 23 especialistas de diversas áreas (filósofos, antropólogos, abogados, literatos y médicos) con aspiraciones polimatistas, se da a la tarea de explorar los puntos de contacto entre los dos grandes paradigmas de la medicina moderna: la basada en evidencias (MBE) y la basada en valores (MBV).

Dividido en tres partes (aspectos teóricos, dignidad humana y estudios empíricos) Valores y virtudes ofrece una visión integral de la medicina al explorar los diversos factores que inciden en la práctica clínica. La finalidad ostensible de este análisis multifacético es ampliar nuestro entendimiento de la complejidad de los dilemas éticos que se generan como consecuencia del choque entre la tecnología, de la cual dependemos cada vez más para el diagnóstico y tratamiento de enfermedades, y la necesaria dimensión humana del encuentro 
entre personas que supone la práctica médica. Por otra parte, este libro, cuyo lenguaje es claro, sencillo y libre de jerga técnica o académica, permite a los lectores legos en materia de ética clínica familiarizarse con conceptos clave que les posibilitan entrar en sintonía; tener un lenguaje en común entre disciplinas.

Entre sus capítulos más atractivos y enriquecedores destacan: "Conocimiento clínico en la práctica médica", en el que se aborda la complementariedad del conocimiento explícito y tácito (puntualizando los tres tipos que integran este último: colectivo, somático, tácito-relacional) y se propone un paralelismo entre la tensión que surge al tratar de reconciliarlos y aquella que permea la integración entre MBE y la MVB.

Digno de mención es también el apartado dedicado a "Responsabilidad médica en México: aspectos legales", que presenta un recorrido muy completo por las instancias más comunes de mala praxis y las vías legales para resarcir el daño. "Virtudes en medicina" combina exitosamente una revisión de los conceptos fundamentales de la ética de la virtud, con una exposición de casos clínicos reales que revelan los complejos dilemas que suponen encuentros cotidianos entre pacientes y personal de salud. Este capítulo resulta particularmente iluminador para lectores poco familiarizados con el razonamiento médico, puesto que pone de manifiesto los procesos mentales que ocurren del otro lado del escritorio en la consulta, desde el asiento del clínico. Permite tener una visión más equitativa de decisiones que podrían parecer arbitrarias o demasiado categóricas.

Por su parte, Ética en obra es una antología de textos literarios que muestran cinco visiones diferentes de los dieciséis valores que permean la interacción entre el personal de salud, los pacientes y sus familias con más frecuencia. Tiene como objetivo declarado complementar el enfoque integrativo del grupo transfuncional en ética clínica. Sus jóvenes compiladores (la mayoría de ellos estudiantes de literatura) han hecho un buen trabajo de selección de poemas, cuentos, ensayos, fragmentos de novela y teatro de la literatura mundial. Su ambición de lograr un balance entre tradiciones de diversas épocas y locaciones del mundo es evidente en su intercalación de autores paradigmáticos del canon occidental como Víctor Hugo, Oscar Wilde, Shakespeare, Leo Tolstoi, Franz Kafka y Walt Whitman con escritores y filósofos latinoamericanos, del subcontinente indio, de oriente medio y lejano, algunos muy conocidos como Amado Nervo, Rabindranath Tagore o Gibrán Jalil Gibrán, otros poco estudiados o incluso anónimos. Necesariamente, puesto que se trata de un volumen breve, en la mayoría de los casos son pasajes cortos, que hacen las veces de aperitivo para estimular el apetito lector, permitiendo que cada quien pueda ahondar en los temas y autores de su preferencia.

Entre sus inclusiones más laudables cabe resaltar "Una propuesta modesta" de Jonathan Swift, autor dieciochesco conocido en nuestro contexto sociohistórico casi exclusivamente por sus Viajes de Gulliver (sátira cáustica de la sociedad inglesa de su momento, con frecuencia malentendida como libro de aventuras para niños). Este ensayo de corte misántropo, en dicción irónica sostenida, resulta por completo pertinente de ser retomado en nuestros tiempos, en que los modelos neoliberales y tendencias de utilitarismo mal comprendido privilegian la idea de modernización y crecimiento económico por encima del bienestar real, muchas veces a costa de la dignidad humana. Quizá una breve introducción al texto hubiera ayudado a poner de manifiesto la intencionalidad irónica de Swift de manera más clara. Pese a esta omisión, que probablemente obedece a consideraciones de espacio, la inclusión de la "Propuesta modesta" en el apartado de dignidad es por completo acertada. Asimismo 
merecedora de encomio por su atino como ilustración agridulce de la perversión humana es la elección de "El collar" de Guy de Maupassant, "El amigo fiel" de Oscar Wilde, "El jorobadito" de Roberto Artl y el fragmento de "Ante la ley" de Franz Kafka como ejemplos irónicos de los valores de "honestidad", "fidelidad", "tolerancia" y "justicia", respectivamente. Vale la pena, también, detenerse de manera particular en las secciones de "respeto", "belleza" y "libertad".

Desde sus distintos enfoques, Valores y virtudes y Ética en obra resultan de interés para especia- listas de diversas áreas del saber, como lo son sus autores. Ante todo, son libros para pacientes. Esta aseveración parte del supuesto que todos, en algún momento de nuestras vidas, hemos estado, o habremos de estar, en esa situación de malestar que nos lleva por una parte a depositar nuestra confianza y esperanza en los profesionales de salud, y por otra a aprender a tomar las decisiones más acertadas para alcanzar el mayor bienestar posible.

Anaclara Castro Santana CONACYT-INP 